\title{
Elastomeric ozone concentration detector
}

\author{
P.H. Mott*, C.M. Roland \\ Chemistry Division, Code 6126 Naval Research Laboratory Washington, DC 20375-5342, USA
}

\begin{abstract}
Micron-sized surface cracks develop in polybutadiene when stretched and exposed to ozone. The consequent reduction in the transparency of the rubber provides a method for quantifying the ambient ozone concentration. The rate at which opacity develops depends linearly on the amount of ozone, and increases with increasing strain. This method of detecting atmospheric ozone has high sensitivity (1 ppb) and a broad dynamic range. The crack morphology can be interpreted in terms of nucleation and growth. (C) 2001 Elsevier Science B.V. All rights reserved.
\end{abstract}

Keywords: Ozone; Rubber; Crack; Light transmission; Transparency

\section{Introduction}

Stress cracking due to ambient ozone is normally a handicap, diminishing the appearance and serviceability of rubber products. Earlier studies of this phenomenon established the existence of three regimes [1,2] - (1) at sufficiently low stresses, no surface cracking occurs; (2) at intermediate stresses, a small number of cracks grow to substantial size, with concomitant reduction in the failure properties; (3) high stresses yield a plethora of cracks, but the mechanical properties are minimally affected.

This behavior can be explained using fracture mechanics [3,4]. The tensile stress, $\sigma_{c}$, necessary to form an ozone crack is given by

$\sigma_{\mathrm{c}}=\left(\frac{G_{c} E}{\pi a}\right)^{1 / 2}$

where $E$ is Young's modulus, $a$ is the crack depth, and $G_{\mathrm{c}}$ is the fracture energy (ca. $0.1 \mathrm{~J} \mathrm{~m}^{-2}$ ). For $E=1$ $\mathrm{MPa}$ and an initial value $a=20 \mu \mathrm{m}$ (corresponding to the typical inherent flaw size in rubber [5]), Eq. (1) yields a critical tensile stress of $50 \mathrm{kPa}$ at a strain of $5 \%$. At stresses below this value (regime 1), the intrinsic flaws are too small to produce ozone cracking. At stresses larger than $\sigma_{\mathrm{c}}$ (regime II), only the largest flaws are sufficient to effect crack growth, resulting in large, isolated cracks. At the tip of cracks, stress magnifica-

\footnotetext{
* Corresponding author.
}

tion increases with crack growth, until the critical tearing energy is exceeded, whereupon the sample fails [6]. In regime III, the stress in the bulk of the material is large enough to initiate cracks, resulting in cracks uniformly covering the surface. This abundance produces a translucent (frosted) appearance. At the crack tips, however, the stress amplification is low, due to the presence of closely spaced neighboring cracks ('stress alleviation'). Cracks continue to grow, but because the stress concentration is minimal, the critical tearing energy is never exceeded. Since the damaged layer at the surface is only a small fraction of the total volume, the failure properties of the elastomer remain the same, notwithstanding the frosted appearance [7].

From observations on isolated cuts in rubber specimens, the crack growth rate has been shown to be independent of stress, depending only on ozone concentration for a given material [8]. At temperatures sufficiently above the glass transition temperature, the ozone concentration is the rate-limiting factor for crack growth $[9,10]$.

The object of most studies of ozone cracking is to improve the resistance to it. Hence, such experiments usually employ very high ozone concentrations, e.g. $10^{5}$ ppb, far above normal ambient levels of 10-100 ppb $[11,12]$. There have been some attempts to use the cracking behavior of rubber as a measure of ozone concentration. For e.g. a differential creep technique was developed, base on the reduction of cross-sectional area accompanying ozone deterioration of rubber [13- 
15]. Another approach is to measure the length of cracks, and deduce the ozone concentration by comparison to calibration curves [11,16,17]. These methods are fraught with problems; for e.g. the distribution of crack lengths is a complex function of time and strain, and depends nonlinearly on ozone concentration [11].

There are many other ways to measure the concentration of ambient ozone $[18,19]$. Accurate commercial instruments are expensive and not suitable for field use, while portable methods suffer from poor accuracy, or are susceptible to interference from vibration or other chemicals. The need for accurate, portable ozone detection methods has grown of late, a result of regulatory compliance and health concerns. Ambient ozone levels as high as $244 \mathrm{ppb}$ have been measured recently in the United States [20]. This is more than twice the Environmental Protection Agency's 'Air Quality Standard' (120 $\mathrm{ppb}$, averaged over $1 \mathrm{~h}$ period, and $80 \mathrm{ppb}$ averaging over an 8-h period [21]). In 1997, 38 metropolitan areas, having a population of 100 million, do not meet this standard [22]. The US Occupational Safety and Health Administration has established a workplace ozone 'permissible exposure limit' of $100 \mathrm{ppb}$, averaged over $8 \mathrm{~h}$ [23].

In this paper, we describe a method to quantify ambient ozone levels from measurement of the optical clarity of rubber films [24,25]. The method provides high sensitivity, a broad dynamic range, while circumventing many limitations of commercial techniques.

\section{Experimental}

Results reported herein were obtained using a blend of two commercial 1,4-polybutadienes, 83 wt.\% Diene

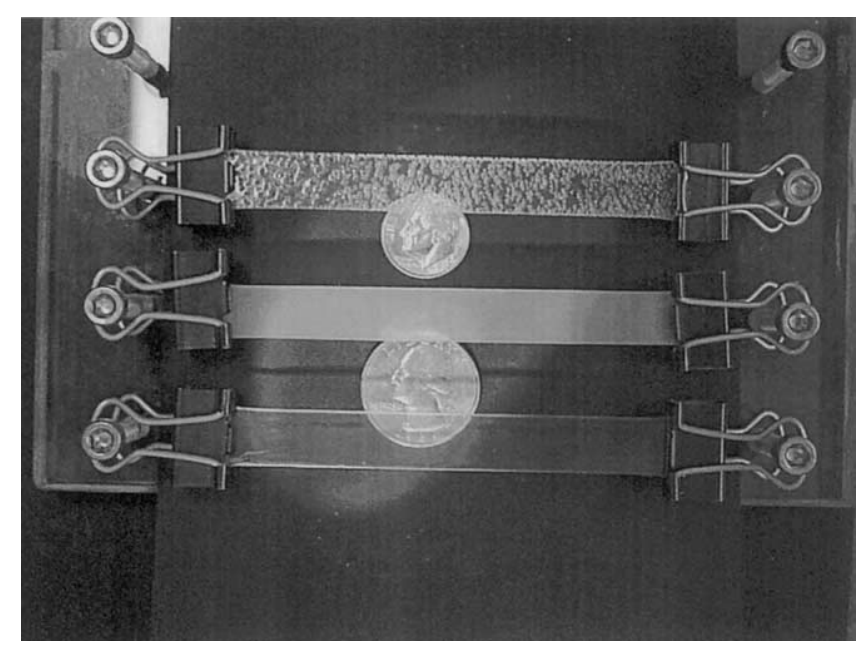

Fig. 1. Photograph of the three regimes of ozone cracking. All samples were exposed to $10 \mathrm{ppb} \mathrm{O}_{3}$ for $24 \mathrm{~h}$. Top: regime II, sample strained 18\% during exposure; middle: regime III, sample strain $121 \%$; bottom: regime I, sample unstrained.
55AC10 (Firestone Synthetic Rubber \& Latex Company) and 17\% Taktene 1203 (Bayer Corporation). The curative, dicumyl peroxide, was dissolved in hexane, and aliquots added to the raw polymer to yield $0.03-$ $0.06 \mathrm{phr}$. Following evaporation of the solvent, the rubber was mixed on a two-roll mill, followed by compression molding $\left(40 \mathrm{~min}\right.$ at $\left.150^{\circ} \mathrm{C}\right)$ to yield cured films $(65 \times 13 \times 1.6 \mathrm{~mm})$.

A steady stream $(6 \mathrm{l} / \mathrm{m})$ of ozone-laden air (Environics Series 300 ozone generator) was fed into a chamber, with a return stream sampled in order to analyze the ozone concentration. The sample was fitted in a frame, which was placed in the chamber with minimal disturbance. The sample was then elongated with an external pull rod. The imposed strain was maintained constant during the experiment.

A $\mathrm{HeNe}$ laser beam (Uniphase 1104P) was expanded to illuminate a $10 \mathrm{~mm}$ diameter spot on the rubber film, with the transmitted light was focused onto a photodiode (EG\&G Inc. UV100). The transmitted light intensity was normalized by the value measured immediately after stretching the rubber; this ratio is referred to as the relative transmission.

\section{Results and discussion}

\subsection{Regimes of behavior}

Fig. 1 illustrates the three regimes of behavior. These samples were exposed to $10 \mathrm{ppb}$ ozone for ca. 1 day, either unstrained (regime I), strained 18\% (regime II), or strained $121 \%$ (regime III). The unstained sample is indistinguishable from unexposed rubber, while the regime II sample has large, distinct cracks. The regime III sample has become completely opaque, due to the cracks uniformly covering its surface. These are 5-10 $\mu \mathrm{m}$ in depth and spaced $20 \mu \mathrm{m}$ apart.

The boundary between regimes II and III is illustrated more clearly in the optical micrographs displayed in Fig. 2, in which two samples with slightly different moduli were used. Both rubbers were held at $40 \%$ elongation for $30 \mathrm{~min}$, while exposed to $100 \mathrm{ppb}$ ozone; this corresponds to stresses of 0.36 and $0.28 \mathrm{MPa}$, respectively. In the more cross linked rubber, the surface cracks are not apparent without magnification (regime III). Increasing the strain does not change the appearance of the frosting. However, in the softer rubber, cracks are easily discernable. When the stress in this sample is reduced by lowering the strain, fewer but larger cracks are produced. This is regime II behavior.

\subsection{Opacity}

The relative transmission is plotted in Fig. 3 as a function of exposure time for five ozone concentrations. 

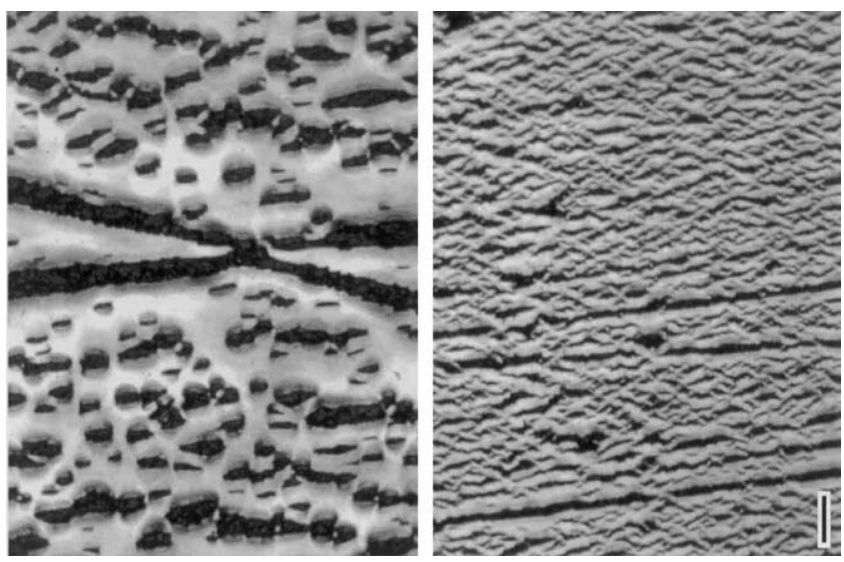

Fig. 2. Transmission optical microgragh, comparing the cracks for two rubbers of different modulus. The strain was $40 \%$ (stress $=0.28$ and $0.36 \mathrm{MPa}$ for left and right samples, respectively), applied for 30 min in $100 \mathrm{ppb} \mathrm{O}_{3}$. The bar in the lower right hand corner indicates $100 \mu \mathrm{m}$.

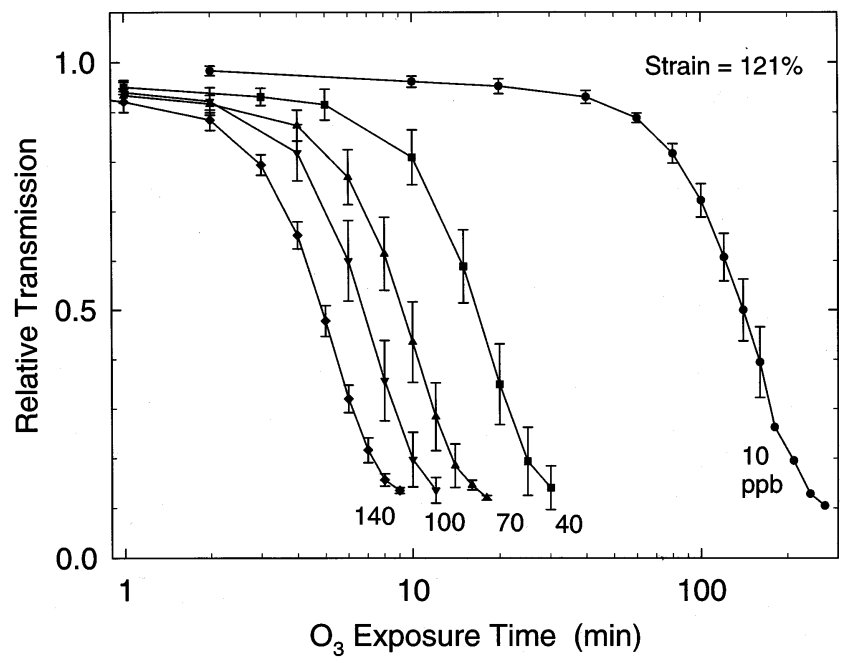

Fig. 3. Relative transmission (averaged of four or five trials) of rubber, strained $121 \%$, versus exposure time for different ozone concentrations. The error bars are one standard deviation (S.D.).

The error bars represent the standard deviation of the data. Increasing the ozone concentration decreases the time to achieve opacity. When the relative transmission is about $10 \%$, the appearance of the rubber is similar to the frosted sample seen in Fig. 1.

The parallelism of the curves in Fig. 3 indicates that variation of the ozone level only changes the time scale of the process. The data can be horizontally shifted to yield a 'master curve', as shown in Fig. 4. The shift factors used to obtain this superposition are displayed as an inset to the figure. These shift factors for the abscissa have a linear dependence on ozone concentration. This behavior simplifies obtaining a universal relationship between rubber opacity and ozone concentration.

\subsection{Effect of strain}

Fig. 5 illustrates that changing the strain has a comparable effect to changing the ozone concentration. A decrease of the strain from 121 to $76 \%$ retards the loss of optical clarity, but without affecting the shape of the curve. Thus, the sensitivity of the rubber to ozone may be adjusted by changing its stretch, without changing the nature of the calibration. This raises the question of whether crack growth rate depends on the applied strain (i.e. stress), in contradiction to earlier results.

The effect of strain is further explored in Fig. 6, which displays an optical micrograph of ozone-induced cracks around stress-raising flaw (a $0.5 \mathrm{~mm}$ hole) inten-

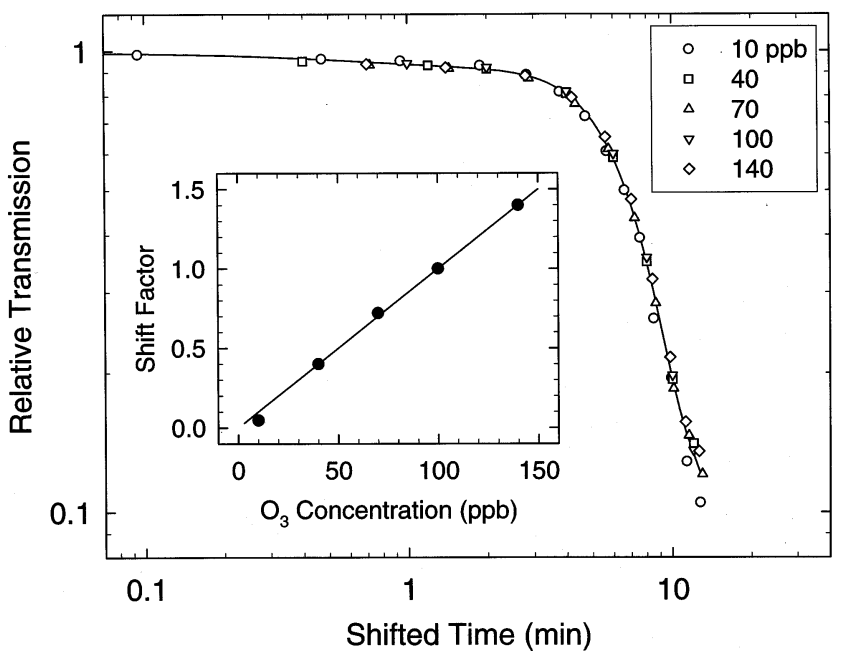

Fig. 4. Ozone cracking 'master curve' obtained by superposition of the data in Fig. 3. Error bars have been omitted for clarity. The inset shows the factors by which the abscissa values were shifted in order to generate the master curve.

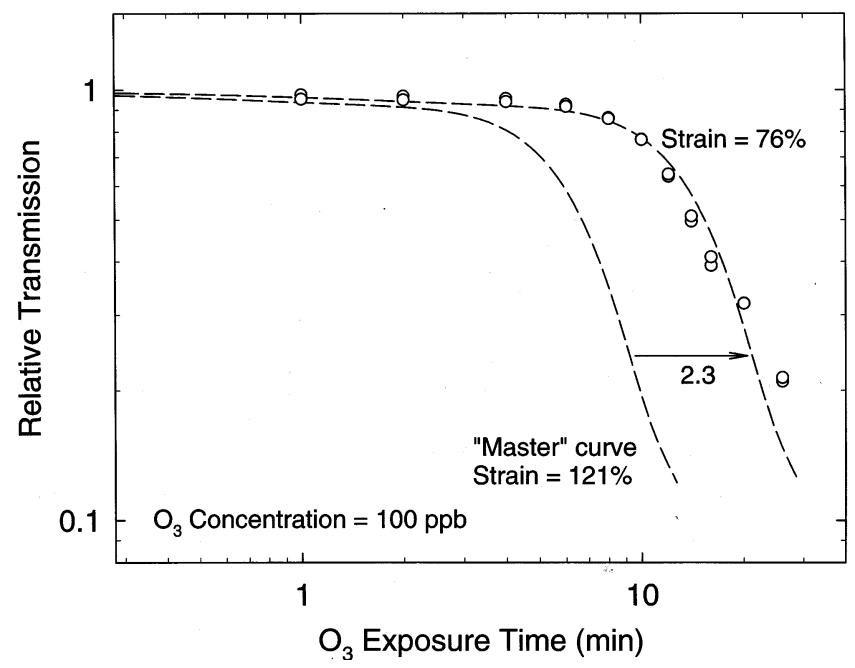

Fig. 5. Comparison of light transmission at two different strains. The open circles are measurements for samples stretched $76 \%$, while the broken lines are from the master curve in Fig. 4. The decrease in strain increased the response time by a factor of 2.3 . 


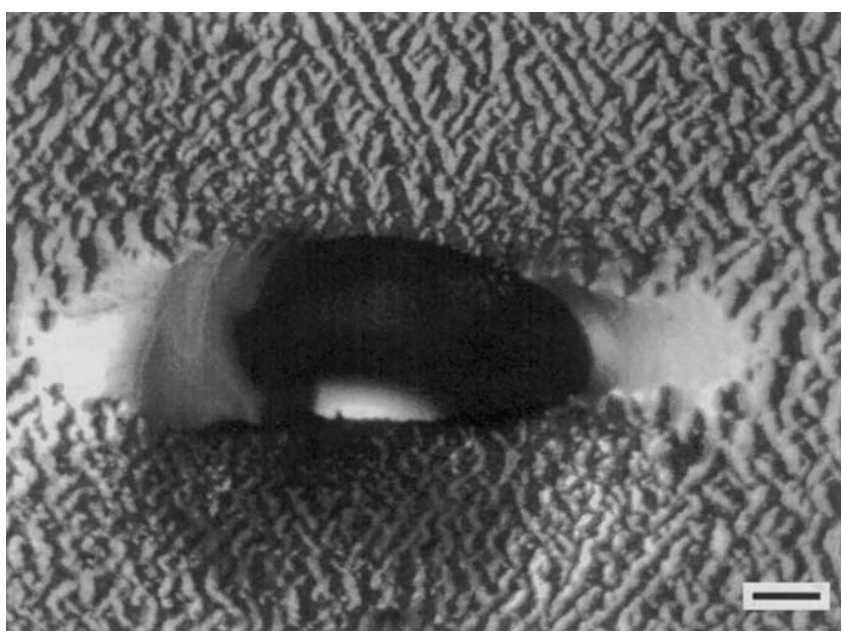

Fig. 6. Transmission optical microgragh of ozone cracks surrounding a stress-raising flaw (a hole) of about $0.5 \mathrm{~mm}$ diameter. The uncracked region shows where the stress has been relieved, regime I behavior. Elsewhere, whether close to the hole or far away from it, the cracks are of uniform length and depth, demonstrating that the crack growth rate does not depend on stress. The bar indicates 100 $\mu \mathrm{m}$.

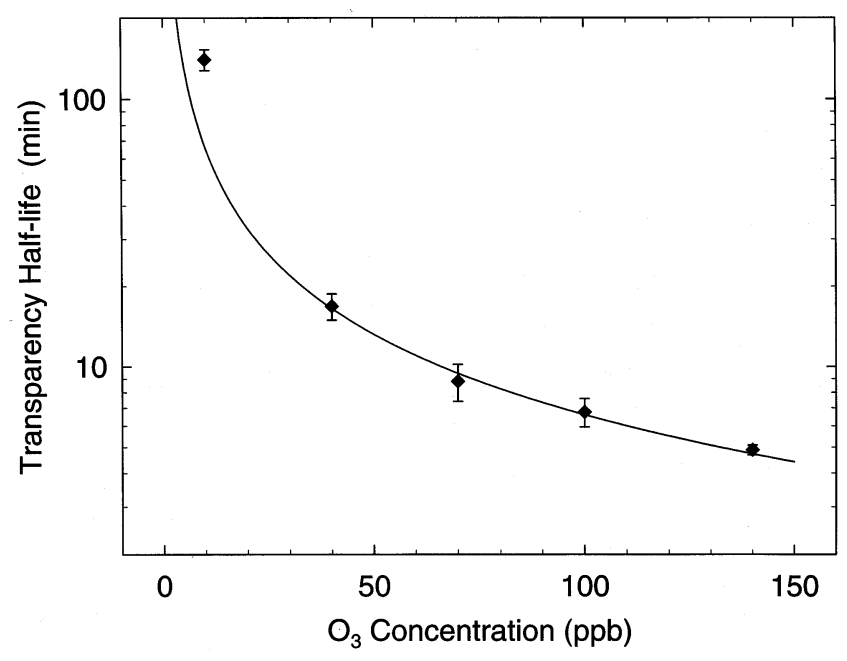

Fig. 7. The time required for loss of half the initial transparency versus ozone concentration. The smooth curve is derived from Fig. 4; the points are measured data. The error bars represent one standard deviation (S.D.).

tionally put into the sample. In the regions where the stress is relieved, there are no cracks, consistent with regime I behavior. However, where the stress is increased, the cracks are the same size as those far from the hole. This demonstrates that the increasing the stress does not change the crack growth rate, as reported earlier [8]. For the relatively high stress in regime III, it is apparent that many more cracks are initiated than grow. Further microscopic examination of other specimen reveals that growth of many cracks terminate and close, as a result of strain relief from neighboring cracks.
Consequently, the sensitivity of frosting to strain (Fig. 5), which at first sight contradicts the conclusions of earlier studies [8] that ozone crack growth rates are independent of stress, is in fact due to the stress-dependence of crack initiation.

\subsection{Ozone detection}

The loss of optical clarity due to ozone-induced stress cracking is an obvious means for detecting ozone. The parallel response (Fig. 3), along with the linearity of the shift factors used to obtain a master curve, facilitate quantitative measurement. The ability to change the sensitivity by changing the strain allows for a wide range of concentrations and measurement times. The range can be extended further by altering the formulation of the rubber.

To illustrate one possible scheme for ozone detection, Fig. 7 shows the time required for a $50 \%$ reduction in the initial transmitted intensity as a function of ozone concentration. The smooth curve is the prediction based on fits to the experimental data in Fig. 4; the points are measurements. The agreement is excellent, excepting the datum at $10 \mathrm{ppb}$. At this low level, results are less reliable due to systematic error in controlling the output of the ozone generator.

\section{Summary}

Using light transmission through stretched rubber, ambient ozone can be routinely measured down to 1 $\mathrm{ppb}$ levels. The sensitivity and dynamic range of the technique can be adjusted by changing the applied strain or by changing the modulus of the rubber. This variability of the sensitivity is due to the dependence of crack initiation on the applied stress. The crack growth rate per se is independent of the strain.

\section{Acknowledgements}

We are grateful to Environics Inc. for the use of their ozone apparatus, and thank Professor A.S. Argon for helpful discussions. This work was supported by the Office of Naval Research and the Naval Research Laboratory under contract number N00014-94-C2195.

\section{References}

[1] R.G. Newton, J. Rubber Res. 14 (1945) 27.

[2] R.G. Newton, J. Rubber Res. 14 (1945) 41.

[3] M. Braden, A.N. Gent, Kautschuk Gummi 14 (1961) WT157.

[4] E.H. Andrews, D. Barnard, M. Braden, A.N. Gent, in: L. Bateman (Ed.), The Chemistry of Rubberlike Substance, Wiley, NewYork, 1963 Chapter 12. 
[5] I.S. Choi, C.M. Roland, Rubber Chem. Technol. 69 (1996) 591.

[6] G.J. Lake, P.B. Lindley, J. Appl. Polymer Sci. 9 (1965) 2031.

[7] C.M. Roland, J.W. Sobiesky, Rubber Chem. Technol. 62 (1989) 683.

[8] M. Braden, A.N. Gent, J. Appl. Polymer Sci. 3 (1960) 90.

[9] A.N. Gent, J.E. McGrath, J. Polymer Sci. A3 (1965) 1473.

[10] A.N. Gent, in: James E. Mark, Burak Erman, Frederick R. Eirich (Eds.), Science and Technology of Rubber, Second ed, Academic Press, San Diego, 1994 Chapter 10.

[11] E. Serrano, M. Castro, A. Macias, Atmospheric Environment Part A-General Topics 27 (1993) 431.

[12] G.J. Lake, P.G. Mente, Polymer Degrad. Stability 49 (1995) 193.

[13] F.L. Roth, R.D. Stiehler, India Rubber World 118 (1948) 367.

[14] R.F. Shaw, S.R. Adams, Anal. Chem. 23 (1951) 1649.

[15] A.G. Veith, American Society Testing Materials, vol. 229, Technical Publication, 1958, p. 97.

[16] J.S. Rugg, Anal. Chem. 24 (1952) 818.

[17] A.G. Veith, Rubber Chem. Technol. 45 (1972) 293.
[18] G. Gordon, W.J. Cooper, R. Rice, G. Pacey, in: G. Gordon, W.J. Cooper, R. Rice, G. Pacey (Eds.), Disinfectant Residual Measurement Methods, Second ed, American Water Works Association Research Foundation, Denver CO, 1992.

[19] Air Quality Criteria for Ozone and Related Photochemical Oxidants US EPA Report No. EPAI6OOIP-93I004aF, July 1996.

[20] Aerometric Information Retrieval System, US Environmental Protection Agency, Office of Air Quality Planning and Standards, Information Transfer and Program Integration Division (ITPID), Research Triangle Park, North Carolina.

[21] Federal Register, 40 CFR part 50, 18 July 1997.

[22] Federal Register, 63 FR 2804, 5 June 1998.

[23] Code of Federal Regulation, 29 CFR 1910.1000, table Z-1.

[24] C.M. Roland, P.H. Mott, Atmospheric Ozone Concentration Detector, patent \# 5972714, issued 26 October 1999.

[25] P.H. Mott, C.M. Roland, NASA Tech Briefs, September 1997, page $12 \mathrm{a}$. 